\section{ENTREVISTA COM WANDERSON FLOR DO NASCIMENTO}

Por Cláudia Cisiane Benetti (UFSM)

Simone Freitas Gallina (UFSM)

Elisete Tomazetti (UFSM)

Graduado em filosofia, especialista sobre o ensino de filosofia, mestre em filosofia e doutor em bioética pela Universidade de Brasília (UnB). É professor

Adjunto do Departamento de Filosofia da UnB, do Programa de Pósgraduação em Bioética (FS-UnB), do Programa de Pós-Graduação em

Metafísica (IH/UnB) e Co-líder do Grupo de Estudos e Pesquisas em Educação, Raça, Gênero e Sexualidades Audre Lorde - GEPERGES Audre

Lorde (UFRPE/UnB-CNPq). Pesquisador das áreas de Filosofia Africana, Interfaces entre a filosofia e a educação, Ética, Filosofia Política e, também, das bases conceituais da Bioética. Pesquisa questões de

subjetividade/subjetivação com o aporte das teorias de gênero, dos feminismos, da psicanálise e do instrumental analítico produzido por Michel

Foucault. Investiga relações raciais, saúde da população negra,

religiosidades e diversidades de gênero e de orientação sexual, direitos humanos, estudos sobre a colonialidade e suas repercussões na educação

(sobretudo, no que diz respeito à formação docente) e na Bioética. (Texto informado pelo autor)

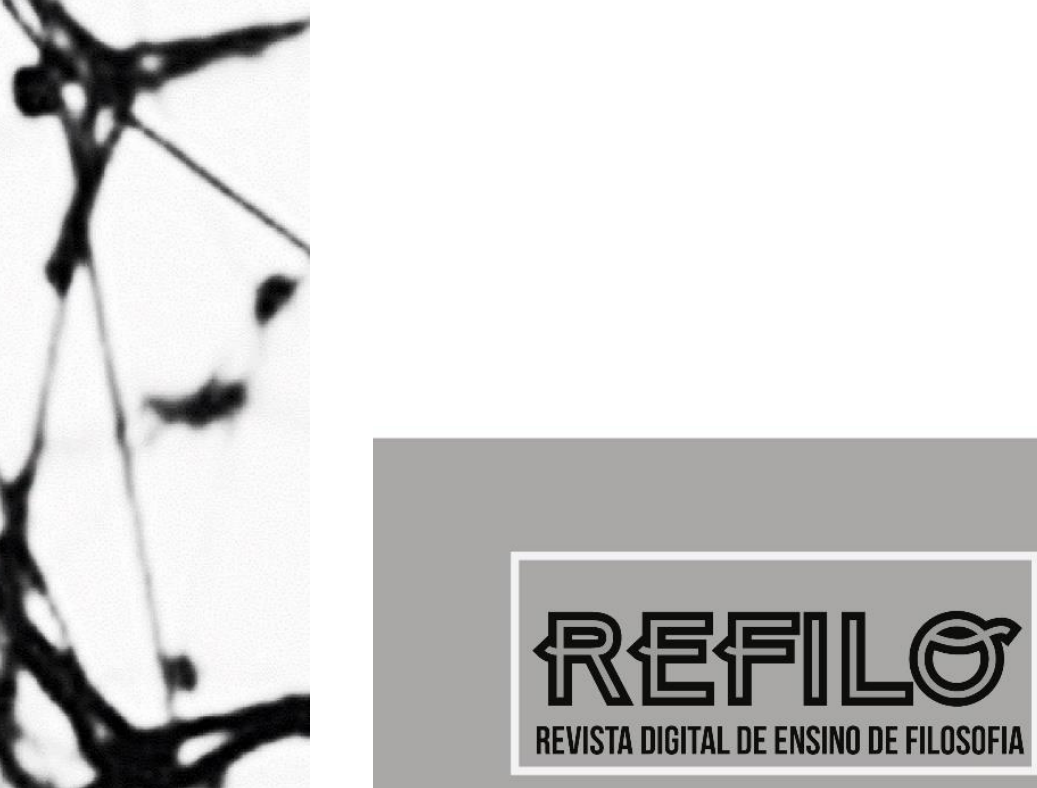

UNIVERSIDADE FEDERAL DE SANTA MARIA/UFSM SANTA MARIA, RS, BRASIL ISSN 2448-0857

PERIODICOS.UFSM.BR/REFILO FACEBOOK.COM/REVISTAREFILO REFILOREVISTA@GMAIL.COM 
Revista Refilo: Professor Wanderson, de antemão gostaríamos de agradecer sua disponibilidade em realizar esta entrevista para a Refilo e iniciaremos por uma questão que é sobre sua trajetória intelectual, sua formação e como se construiu sua inserção em estudos de Filosofia Africana. Pode nos falar brevemente sobre isso?

Wanderson Flor do Nascimento: Eu quem agradeço o convite e a oportunidade de interagir com o projeto interessantíssimo da REFILO e com vocês.

Eu me interessei pela filosofia ainda no Ensino Médio. Gosto de práticas que inventam e tentam entender mundos. O pensamento, a política e as artes me parecem possibilidades interessantes de criar mundos: mundos pensados, imaginados, desejados.

Guiado por esses afetos, iniciei a graduação em filosofia, na Universidade de Brasília (UnB), em 1996. Optei pela licenciatura por questões meramente práticas, imaginando ter um emprego quando me formasse. Entretanto, na medida em que eu adentrava pelo curso, começava a ver que as relações entre a filosofia, a educação e o ensino não eram apenas profissionais. Essa percepção me conectou, de modo definitivo, com as discussões sobre ensino de filosofia e filosofia da educação.

Junto desse percurso, tive a sorte de ter uma formação completamente atravessada por perspectivas que tencionavam com o estado de coisas político no qual eu estava inserido. Já no meu primeiro semestre, segui o curso de "Introdução aos Estudos da História" com a professora Tânia Navarro Swain, que me trouxe a problematização feminista como fundamental para compreender a epistemologia e desconfiar que a produção do conhecimento não pode ser desligada da política. Adentrei no Grupo de Estudos Feministas (GEFEM) coordenados pela profa. Tânia, o que me fez, também, com que toda a minha formação tivesse um atravessamento fundamental da crítica feminista, além de ter me apresentado um dos grandes marcos teóricos de minha trajetória: Foucault. 
Em meu terceiro semestre, ingressei, também, como estagiário, no Núcleo de Estudos Afro-Brasileiros (NEAB), na época coordenado pela profa. Glória Moura. Minha aproximação com o Núcleo atendia a uma necessidade existencial de que eu estivesse mais perto de minha própria ancestralidade, conhecendo-a melhor, pensando-a.

A experiência de ter me aproximado do GEFEM e do NEAB me levou a me interessar, cada vez mais, pelo trabalho intelectual e ativista com as denominadas "diversidades", tanto racial, quanto de gênero, sexualidade e religiosa. Este fato marcou definitivamente minha trajetória formativa e me direcionou para o estudo, em ética e filosofia política, das questões vinculadas com a subjetividade e os processos de subjetivação, campo com o que me ocupo ainda hoje.

No percurso de minha licenciatura, iniciei, em 1999, de modo mais intenso, os contatos com o ensino de filosofia através da participação no Projeto Filosofia na Escola (Filoesco), coordenado à época por Ana Miriam Wuensch, do Departamento de Filosofia, por Lúcia Helena Pulino, do Instituto de Psicologia e por Walter Kohan, que na época trabalhava na Faculdade de Educação da UnB.

Este projeto realizava a formação continuada de estudantes de diversos cursos da UnB e de docentes escolas da rede pública de ensino do DF para o trabalho de filosofia com crianças e adolescentes. Esta experiência modificou, mais uma vez, minha relação com a filosofia e com a educação. A filosofia adquiria, para mim, novas interlocuções: docentes da educação básica, adolescentes e crianças. E essas novas figuras traziam para a filosofia outras e interessantes maneiras de pensála.

Assim, o entrecruzamento das experiências com o GEFEM, NEAB e Filoesco marcaram a minha formação de forma a me colocar sempre na tarefa de pensar a política e politizar o pensamento, desde o contexto da formação, entendendo a educação como uma tarefa que é ao mesmo tempo política, moral e cognitiva. Me alinhei, deste modo, a uma proposição crítica do ensino da filosofia que se ocupou das "diversidades". 
Durante a conclusão de minha graduação, comecei a cursar uma especialização sobre o ensino da filosofia, organizado pelo professor Walter Kohan e que contou com importantes nomes da filosofia da educação, do ensino da filosofia e de outras reflexões em torno da educação, como Antônio Joaquim Severino, Guilhermo Obiols, Sílvio Gallo, Pablo Gentili, Alejandro Cerletti, Jorge Larrosa, Ana Miriam Wuensch, David Kennedy, Tomaz Tadeu da Silva, Angélica Sátiro entre outras/os. Esta etapa da formação reforçou a necessidade de manter uma reflexão constante sobre minha prática como professor. E, a partir daí passo a me ver, sempre, como docente em formação.

Logo em seguida, inicio o mestrado pesquisando, na companhia de Foucault, a possibilidade de uma ética sem universais, sem danos aos outros, uma ética particularista que não abra espaços para a violência, vinculando a ética e a política. E o vínculo com a educação se mantém na discussão sobre a autonomia, sobre o que também trabalhei na monografia de especialização.

Durante o mestrado é sancionada a lei federal 10.639/2003, que demandava que nas escolas de ensino fundamental e médio se inserissem conteúdos de história e cultura africana e afro-brasileira. Desde aí, inicio minha aproximação com as filosofias africanas, buscando entender como a filosofia deveria participar desse processo instaurado pela lei.

No doutorado, retorno, de modo mais intenso, ao estudo das relações raciais e das presenças africanas no Brasil, só que desta vez no campo da bioética, buscando oferecer bases decoloniais para pensar esta importante ferramenta no contexto do Brasil e da América Latina. O contexto da formação segue presente nas reflexões que estabeleci sobre as éticas da vida.

Desde que comecei o trabalho docente na UnB, em 2006, venho buscando sempre relacionar esses campos de interesse com a formação de professoras/es de filosofia e, também, de outras/os estudantes da universidade interessados em aprofundar as reflexões sobre formação, política e a pluralidade de experiências na nossa sociedade. 
Revista Refillo: Queremos Ihe ouvir sobre relações entre a Filosofia Africana e Filosofia Afro-brasileira e implicações destas para a ressignificação de um olhar sobre a história/cultura brasileira?

Wanderson Flor do Nascimento: Falar sobre essas relações implica retomar os debates sobre a própria cultura brasileira. E, também, sobre aquilo que na cultura se relaciona com a filosofia. Pouco refletimos sobre as heranças de nossa cultura que não sejam as europeias. Sabemos que a história e a cultura são elementos fundamentais para compreendermos quem somos. E tanto mais saibamos sobre esses elementos, mais próximas/os
"Pouco refletimos sobre as heranças de nossa cultura que não sejam as europeias. Sabemos que a história e a cultura são elementos fundamentais para compreendermos quem somos. E tanto mais saibamos sobre esses elementos, mais próximas/os estaremos de uma imagem mais nítida de nossa própria identidade."

estaremos de uma imagem mais nítida de nossa própria identidade. Não se trata, aqui, de escolher entre conhecer os elementos europeus que nos constituíram e os africanos e indígenas, mas em pluralizar olhares sobre nossa formação históricocultural de modo a ampliar horizontes sobre nós, nossos valores, saberes e práticas.

Desde a perspectiva das imagens que temos sobre as culturas das quais somos herdeiras/os, pensar as filosofias africanas e afro-brasileira amplia nosso olhar sobre nossa cultura e sobre nossa história. Há elementos que herdamos do continente africano que sequer sabemos. Há saberes que reproduzimos e utilizamos sem saber ao certo suas origens. E há, também, muita coisa que se produziu nos diversos países africanos que deixamos de saber por não explorarmos as reflexões produzidas nesses lugares. 
"Como a filosofia foi uma das partes envolvidas nesse

processo de

desumanização, nada mais

justo que ela também se empenhe em desconstruir este preconceito que ajudou a criar."
E não se trata apenas de uma ampliação da erudição. É um reconhecimento da própria humanidade das pessoas africanas, que foi negada durante $\bigcirc$ processo colonial escravagista, do qual não nos recuperamos, de todo, ainda...

Como sabemos, a filosofia é entendida como um modo sofisticado de pensar, que demanda um determinado rigor. Sabemos, também, que a história da modernidade foi marcada pela imagem inferiorizada, inclusive intelectualmente, de povos não ocidentais, entre eles, as pessoas do continente africano. Filósofos importantes do cânone moderno, como Hume, Kant e Hegel participaram ativamente da construção e/ou justificação dessa imagem.

Esse ideário findou por criar um hábito de não esperarmos que povos entendidos como desprovidos de um intelecto pleno, como o seria o dos europeus, pudessem produzir esse pensamento sofisticado que é a filosofia. Nesse contexto, estudar e difundir as filosofias africanas é um dos modos de descontruir essa imagem equivocada e racista que, de algum modo, ainda nos assombra. E, com isso, afirmar a humanidade dos povos negros. Como a filosofia foi uma das partes envolvidas nesse processo de desumanização, nada mais justo que ela também se empenhe em desconstruir este preconceito que ajudou a criar.

Como as práticas e valores racistas ainda permeiam nossa sociedade - afinal, foram constitutivas dela também - é imperioso que, para desconstruir a presença do racismo em nosso país, envidemos esforços para recuperar os valores, saberes e práticas que foram e são produzidos no continente africano e que, mesmo negados, informam sobre a nossa própria cultura, história e modos de pensar. 
Revista Refilo: Inserindo-nos no campo educacional, quais são as principais questões/enfrentamentos que envolvem 0 ensino de Filosofia Africana em Cursos de Filosofia no Brasil? Dentre estes enfrentamentos o que pode nos dizer sobre racismo epistemológico?

\section{Wanderson Flor do Nascimento: Uma das} mais importantes questões que enfrentamos hoje para pensar o ensino das filosofias africanas nas graduações em filosofia - e, consequentemente, também no ensino médio - é uma curiosa imagem vinculada com o postulado da universalidade da filosofia. Esta representação afirma que a filosofia é filosofia, independentemente do local onde seja produzida. Não faria sentido, assim, falar em uma filosofia africana, em uma filosofia latino-americana, em uma filosofia oriental ou em uma filosofia brasileira. O que haveria seria apenas a filosofia, produzida em qualquer lugar do mundo. E, nessa existência de uma filosofia sem mais, os cursos deveriam aterem-se em estudar as filosofias que a história considerou como mais relevantes.

O ponto nevrálgico dessa questão se relaciona com o fato de que o argumento dessa filosofia sem mais, só funciona para nos referirmos a lugares que foram historicamente subalternizados em esquemas coloniais. Não causa assombro em ninguém que diversos autores respeitados pelo cânone falem em "filosofia ocidental", "filosofia europeia", "idealismo alemão", "filosofia francesa contemporânea" etc. O desconforto geográfico se dá apenas quando a referência não é a Europa, ou suas projeções no restante do Ocidente (notadamente, nos Estados Unidos).

E, curiosamente, embora "a filosofia seja filosofia em qualquer lugar", renitentemente, observamos, em nosso país, a prevalência de um currículo, que podemos chamar de eurocentrado, na formação da graduação: isto é, encontramos normalmente sempre as mesmas abordagens historiográficas nos 
currículos, que visualiza a filosofia nascida na Grécia, passando por Roma, por um medievo europeu com alguns parcos contatos árabes ou judaicos, uma modernidade que está essencialmente vinculada com as filosofias produzidas na Europa Ocidental, principalmente na França, Alemanha e Inglaterra e em uma contemporaneidade que apenas segue as projeções dessa filosofia moderna, ampliando um pouco o escopo de lugares de produção da filosofia, com a inserção, por exemplo, dos Estados Unidos.

Raros são os currículos de graduação brasileiros nos quais se estudem as filosofias produzidas no continente Africano, no Oriente ou na América Latina, como parte das componentes curriculares obrigatórias. Quando pensamos que nossos documentos oficiais sobre o ensino de filosofia, seja na graduação ou no ensino médio, frisam a importância de uma sólida formação em história da filosofia, a questão que fica é porque apenas esse currículo eurocentrado é entendido como fonte para tal formação sólida? A partir de quais parâmetros entendemos que apenas as filosofias produzidas na Europa Ocidental ou nos Estados Unidos resistem ao teste da relevância, sendo que há um quase total desconhecimento das filosofias produzidas em outras partes do mundo?

Uma das denúncias que as filósofas feministas têm feito é de que a constituição da história da filosofia não é apenas um relato objetivo das filosofias naturalmente relevantes e merecedoras de serem estudadas, mas também um reflexo das relações de poder que estão envolvidas na

"Quando pensamos que nossos documentos oficiais sobre o ensino de filosofia, seja na graduação ou no ensino médio, frisam a importância de uma sólida formação em história da filosofia, a questão que fica é porque apenas esse currículo eurocentrado é entendido como fonte para tal formação sólida?" construção dessa história. Esse fato é a justificativa para a quase total ausência de pensadoras nos currículos de filosofia, embora tenhamos muitas delas no transcurso do tempo de existência da filosofia. O mesmo se dá com as populações que se localizam em espaços geopoliticamente subalternizados pelos processos colonizadores.

E é aqui que a presença do que alguns filósofos têm chamado de racismo epistêmico 
se faz notar: Essas populações foram racializadas e essa racialização foi construída em um atravessamento de hierarquias entre essas populações e de suas capacidades cognitivas/intelectuais. E não é preciso que os currículos tenham um tópico do tipo "Por que não estudar as filósofas e filósofos africanos, latinoamericanas/os ou orientais?". Basta não as estudar/os. Esse é um dispositivo perverso, pois ao invisibilizar essas produções, damos às/aos estudantes um modelo de construção da filosofia já excludente, mesmo sem a tematização explícita dos mecanismos de exclusão.

E, tampouco, é comum que tematizemos, na graduação, a participação da filosofia no contexto da criação dessas imagens racistas das populações. Apenas as pessoas dedicadas a essa espécie de ativismo contra o racismo epistêmico têm feito a discussão das muitas contribuições da filosofia às ideologias racistas. E convido a quem acha que isso é meramente acidental ou excepcional na filosofia, que dê uma olhada no interessante volume organizado por Dominique Colas chamado Races et Racismes de Platon à Derrida. Este compêndio de mais de 750 páginas mostra as razões pelas quais o racismo e, também, um certo tipo de enfrentamento a ele, foi presente em toda a história da filosofia ocidental e que apagamento desse debate tem consequências nefastas para a compreensão de como a filosofia é produzida.

"Temos, ainda hoje, uma imensa dificuldade de lidar com temas raciais. É impressionante, por exemplo, que o tema da biopolítica tenha se popularizado nos últimos vinte anos e, não obstante, que obliteremos ou ignoremos o debate iniciado por Foucault sobre o papel fundamental do racismo de Estado para a constituição da biopolítica e na difusão do biopoder."

Temos, ainda hoje, uma imensa dificuldade de lidar com temas raciais. É impressionante, por exemplo, que o tema da biopolítica tenha se popularizado nos últimos vinte anos e, não obstante, que obliteremos ou ignoremos o debate iniciado por Foucault sobre o papel fundamental do racismo de Estado para a constituição da biopolítica e na difusão do biopoder. A filosofia não escapa ao racismo, pois ela também é parte de sua produção e totalmente inserida no contexto das demais 
práticas sociais. E esta é outra das principais questões que dificultam o ensino das filosofias africanas nos cursos de graduação.

Revista Refflo: A partir disso, quais as implicações para os jovens estudantes do E. M. da ausência/presença do ensino de Filosofia Africana nos currículos dos cursos de filosofia no Brasil?

Wanderson Flor do Nascimento: Essa questão pode ser pensada de diversas maneiras. Gosto de abordá-la pela insistência que as discussões sobre ensino de filosofia têm feito sobre a centralidade da história da filosofia no aprendizado filosófico. A história da filosofia não apenas nos informa sobre os conteúdos considerados no trajeto da disciplina, como também tem um efeito performativo ao mostrar os comos que estão envolvidos no fazer filosófico.

Quando percorremos um currículo de filosofia no ensino médio - ou na graduação e não encontramos mulheres, pessoas africanas, indígenas, orientais, latinoamericanas não apenas aprendemos informações sobre o cânone eurocentrado (e suas projeções estadunidenses), mas também aprendemos, sub-repticiamente, sobre o que não se faz e quem não faz parte da prática filosófica reconhecida e prestigiada institucionalmente por nossa sociedade. Um tipo ideal de sujeitos do filosofar e suas características é apresentado de modo indireto nos currículos, informando a estudantes do ensino médio, inclusive, sobre suas potencialidades de se inserir no fazer filosófico desde suas características histórico-sociais, que muitas vezes, assume aspectos de contornos de gênero e raciais.

Outra dimensão importante é a da própria identidade nacional. As filosofias africanas trazem para nossa compreensão elementos que são formadores - mesmo quando negados - de nosso percurso identitário. Negar a estudantes do Ensino Médio o acesso a esses elementos é cercear a possibilidade de nos conhecermos de modo mais acurado.

Revista Refflo: E no âmbito da escola básica, desde 2003, a Lei de Diretrizes e Bases da Educação Nacional (art. 26-A), determina que em todo o currículo dos ensinos fundamental e médio brasileiros estejam presentes conteúdos de história e cultura 
africana e afro-brasileira, em todos os componentes curriculares'. Desde então, como tem sido este processo nas escolas, especialmente em Filosofia? Quais as problematizações que emergem e são cruciais para a formação de professores/as de Filosofia, considerando-se o aspecto da necessidade de ressiginificação das imagens construídas sobre as populações africanas no Brasil?

Wanderson Flor do Nascimento: Infelizmente esta é uma determinação legal pouquíssimo cumprida nas escolas, de modo geral. As muitas avaliações que foram feitas, desde 2013, quando do decênio desta alteração da LDB, têm sinalizado uma baixa aderência às determinações legais. Há uma impressionante resistência na implementação da lei nas escolas, que muitas vezes se focam apenas em datas comemorativas, folclorizantes e exotizadas em torno da cultura negra em nosso país - isso quando o fazem. No ano de 2018, devemos passar por novas grandes avaliações desse artigo da LDB, pois comemoram-se os dez anos de outra alteração do mesmo artigo, que introduziu a necessidade de estudos da história e cultura indígena nos currículos. As discussões que já começaram parecem indicar que o cenário se modificou muito pouco, praticamente nada...

Isso se deve ao próprio racismo e suas ramificações em nossa cultura, que finda por não deixar promover tanto o acesso a esses elementos de conteúdos nas escolas da educação básica, quanto nos cursos de formação docente, seja para o ensino fundamental ou médio.

No tocante à filosofia, o mesmo acontece. Pouquíssimos são os estados do país que têm propostas para o trabalho com a filosofia africana em seus currículos e uma justificativa utilizada é a ausência de materiais didáticos e de formação inicial ou continuada para docentes do Ensino Médio. Somos pouquíssimos professores universitários que se dedicam ao trabalho do ensino da filosofia

1 Conforme blog Filosofia Africana In: https://filosofia-africana.weebly.com/ consulta em outubro 2017. 
africana. Até 2017, dos menos de dez docentes de universidades públicas, federais ou estaduais, dedicados à pesquisa sobre a filosofia africana e sua presença nas escolas por meio da docência; destes, apenas dois estavam lotados em departamentos de filosofia. A maioria está lotada em Faculdades de Educação que, na maioria dos casos, não ofertam disciplinas para as licenciaturas em filosofia voltadas para a formação para o trabalho com as filosofias africanas.

Um fato bastante curioso é que muitas vezes a gestão do currículo não entende que a filosofia deva participar da implementação do artigo 26-A da LDB, se utilizando de uma bizarra interpretação do segundo parágrafo deste artigo, que afirma que "Os conteúdos referentes à história e cultura afro-brasileira e dos povos indígenas brasileiros serão ministrados no âmbito de todo o currículo escolar, em especial nas áreas de educação artística e de literatura e história brasileiras". Tem-se ignorado a expressão "todo o currículo escolar" por meio do entendimento de que apenas a educação artística, as artes e a história deveriam tratar desses conteúdos, interpretando o "em especial", como se fosse um condicionante de exclusividade, como se apenas essas três disciplinas fossem responsáveis por todo esse trabalho. $\mathrm{E}$ isso tem se refletido, também, nos livros didáticos. Pouquíssimos deles tem se dedicado a apresentar conteúdos vinculados às filosofias africanas.

Outras vezes, quando temos um "enorme avanço", temos alguns materiais didáticos que ou problematizam rapidamente o racismo ou tentam discutir alguns elementos da "estética negra", abrindo mão de buscar as produções filosóficas advindas do continente africano. Não que a problematização do racismo ou as discussões culturais afro-brasileiras não sejam importantes. Mas reduzir a dimensão da cultura à estética e da história a uma breve discussão sobre racismo empobrece enormemente as possibilidades de trabalho com as determinações legais, assim como não é suficiente para oferecer esses elementos que chamávamos a atenção como importantes para a compreensão da formação das identidades brasileiras.

Revista Refilo: Ainda, frente à necessidade de combate ao racismo existente no Brasil, no que concerne aos conteúdos curriculares de Filosofia Africana e modos de abordá-los, quais seriam (conteúdos, modos de abordagem) os mais pertinentes para serem ensinados no Ensino Médio? 
Wanderson Flor do Nascimento: Como chamei a atenção antes, uma das características fundamentais do racismo moderno foi a inferiorização de grupos populacionais racializados. Como essa inferiorização sustentou também uma limitação intelectual das pessoas destes grupos, a exploração das diversas produções intelectuais não ocidentais é já uma maneira de mostrar a inconsistência desta suposta inferioridade das pessoas não ocidentais.

"[...] seria importante nos voltarmos para a diversidade de conteúdos e abordagens produzidas no continente africano e, assim, veríamos que as pessoas africanas produzem conhecimento tão sofisticado como em qualquer lugar do mundo, inclusive a Europa e Estados Unidos."

Por isso, seria importante nos voltarmos para a diversidade de conteúdos e abordagens produzidas no continente africano e, assim, veríamos que as pessoas africanas produzem conhecimento tão sofisticado como em qualquer lugar do mundo, inclusive a Europa e Estados Unidos. Assim como no Ocidente, essas outras populações desenvolveram muitas abordagens e metodologias. Percorrer sua diversidade é uma maneira de mostrar a potência do pensamento produzido no continente africano.

Há quem sustente que isso poderia ser feito por meio da criação de módulos de "introdução às filosofias africanas", tornando-os uma espécie de unidade que seria tratada nas três séries do ensino médio, apresentando, assim, autoras/es, temas e problemas que foram tratados pelas filosofias africanas em algum momento do ano letivo. Eu tenho advogado outra possibilidade: que as temáticas, abordagens e autoras/es apareçam distribuídas ao logo de todo ano, dialogando com os outros conteúdos, seja de áreas temáticas da filosofia, como a ontologia, estética, lógica, política, epistemologia etc., apresentando as leituras africanas de temas que se discutem corriqueiramente nas aulas de filosofia ou, para quem trabalha por meio das divisões temporais da história da filosofia, trazer abordagens africanas localizadas na antiguidade, no medievo, na modernidade e no momento contemporâneo.

Esta perspectiva, além de não isolar o trabalho das filosofias africanas em apenas um período do curso, possibilita um diálogo constante, mostrando a pluralidade e 
potência das reflexões e conceitos criados pelas pessoas africanas ao pensarem sobre seus problemas e os problemas do mundo. Também evitaríamos parte das grandes dificuldades que estão vinculadas com a escolha de conteúdos, típica da construção e colocação de um currículo em prática, pois não multiplicaríamos a tarefa da escolha dos conteúdos, apenas multiplicaríamos as abordagens dos conteúdos já selecionados.

Revisła Refilo: Nesse sentido, Wanderson, quais as contribuições da filosofia africana para [re]pensarmos a tradição da filosofia ocidental baseada no par leitura-escrita?

Wanderson Flor do Nascimento: Uma parte importante da discussão contemporânea das filosofias africanas relaciona-se com a crítica metafilosófica da construção do cânone da história da filosofia ocidental (que muitas vezes é lido como o cânone da filosofia, em si). Junto das discussões realizadas sobre o mesmo tema pelas filosofias latino-americanas e orientais, encontramos elementos interessantíssimos para pensar de que modo a construção da história da filosofia é também um gesto político.

Neste sentido, as filosofias africanas são interessantes ferramentas para exercitar a politização do pensamento e avaliar seus alcances e limites. Assim como problematizar, desde uma política epistemológica - ou uma epistemologia política -, a universalidade não apenas dos conceitos, mas também de métodos e descrições do pensamento.

Poderemos nos surpreender não apenas com as distâncias temáticas/metodológicas - uma vez que estas estão vinculadas inexoravelmente com a história - mas também com as semelhanças de algumas ideias, que foram pensadas em tempos diferentes, inclusive podendo nos surpreender com a antecipação de algumas questões importantes que apenas mais tardiamente foram discutidas no Ocidente.

É interessante abordar essas semelhanças não por uma disputa de originalidade ou na lógica de "quem pensou primeiro", mas para mostrar que sendo as pessoas africanas humanas, elas são tão capazes de produzir ideias, conceitos, métodos 
como quaisquer outras pessoas. Não se trata de pensar quem faz a melhor filosofia, mas que há filosofias plurais.

Há que se descontruir a imagem de que 0 continente africano é ágrafo em função da prevalência da tradição oral. Esse tem sido um dos estereótipos utilizados para estabelecer uma tensão entre as filosofias produzidas no Ocidente e as que foram produzidas em outros lugares do mundo (como se não houvesse, inclusive, uma discussão interna no próprio Ocidente sobre a problemática da escrita e da importância da oralidade). A maioria das culturas tem suas relações tensas sobre os modos como lidam com a oralidade e com a escrita (ou outros registros gráficos).

E é importante, nesse contexto, não lidar com as filosofias do mundo em termos comparativos-competitivos. Elas são diferentes e essa diferença nos ajuda a perceber a riqueza do pensamento humano. E uma forte armadilha que acontece, nesse cenário, é a reprodução de imagens do continente africano como atrasado e que se prestam a estabelecer comparações hierarquizadas entre a filosofia moderna do Ocidente e o pensamento tradicional/popular do continente africano, como se no primeiro só houvesse pensamento científico/filosófico/sofisticado e no último só houvesse pensamento supersticioso.

Esse procedimento ignora que há um pensamento popular no ocidente e um pensamento científico/filosófico/sofisticado no continente africano. Há diversos momentos e movimentos na história do pensamento no mundo inteiro e tanto mais sejamos capazes de explorá-los, mais seremos capazes de desconstruir preconceitos que têm marcado as relações entre o Ocidente e seus outros. 
Poderíamos resumir essa resposta afirmando que as filosofias africanas podem ser instrumentos interessantes para uma retomada metafilosófica das tradições filosóficas construídas no mundo, de modo politizado e, com isso, poder também reavaliar a própria tradição ocidental. Não de modo deslegitimador ou destrutivo, mas de maneiras, ao mesmo tempo, problematizadoras, dialógicas e colaborativas.

Revista Refillo: E, por último, considerando o cenário político no Brasil atual, quais são as questões emergentes para o campo estudos/práticas da Filosofia Africana e Filosofia Afro-brasileira? E como você analisa o cenário político educacional atual?

Wanderson Flor do Nascimento: A primeira parte da questão depende do modo como eu responda a segunda. Embora a chamada crise na educação não seja um fenômeno recente, o atual momento conturbado de nossas sociedades, com o avanço de posturas reacionárias, tende a aprofundar e a reorientar os problemas enfrentados no cenário político educacional que vivemos agora.

Esta crise tem movimentos múltiplos: criamos muito em termos de tecnologias e suas aplicações, mas inventamos pouco do ponto de vista das sociabilidades acolhedoras, aprendemos pouco em termos de convivência solidária. Passamos de uma crítica dos valores dogmáticos a uma afirmação de valores violentos despotencializadores. $\mathrm{E}$ isso impacta de modo intenso o cenário político educacional. Em contrapartida, temos visto uma série de movimentos contra hegemônicos de resistência que tem trazido outros ares para lidar com as questões emergenciais e emergentes que cercam nosso presente e que convocam a educação para ocupar um protagonismo na criação de mundos menos destrutivos.

Desde as trincheiras do trabalho com as filosofias africanas, esse cenário apresenta problemas que colocam em questão a função da educação no processo da construção de solidariedades política e histórica entre os povos e, também, na compreensão dos processos que nos tornam o que somos. As filosofias africanas nos convocam a uma descolonização do pensamento de modo a podermos romper com hierarquias naturalizadas que muitas vezes introjetamos em nós. 
Independentemente dos conteúdos filosóficos oriundos do continente africano que estejamos estudando, a aproximação com as reflexões desse continente já nos coloca diante da tarefa de nos descentrarmos das maneiras usuais com as quais fomos ensinadas/os, desde a filosofia, a pensar como imaginamos que funcionam as políticas do pensamento.

Entre surpresas, espantos, alegrias, decepções, ao encontrarmos de tudo no pensamento africano: nos damos por conta de que ali acontece o mesmo que acontece em qualquer lugar do mundo - inclusive resistências importantes a crises. $E$ isso nos coloca perante o quadro de ampliar os horizontes do que desejamos pensar, do que podemos pensar, do que interessa pensar. Pluralizar as perspectivas em torno da filosofia, da educação, dos encontros entre as duas, desde uma politização decolonial do pensamento, pode ser uma ferramenta que nos auxilie a trazer outros olhares para esse cenário obscuro que cerca nosso tempo atual.

"Pluralizar as perspectivas em torno da filosofia, da educação, dos encontros entre as duas, desde uma politização decolonial do pensamento, pode ser uma ferramenta que nos auxilie a trazer outros olhares para esse cenário obscuro que cerca nosso tempo atual." 